I would like to suggest that Socrates' 'symptoms', on the contrary, are a consequence of dissociative phenomena occurring during intense and prolonged introspection. Introspection seems to be an important factor in Spivak et al's original cases (Journal, March 1992, 160, 412-414) as each was alone and thoughtful as well as being distressed and under pressure. In trance states and under hypnosis hallucinations readily occur. A possible objection to this explanation is the high level of arousal suffered by Spivak et al's cases: this is no obstruction to trancelike states, as demonstrated by the work of Milton Erikson, who at times induced such states at the same time as increasing arousal.

Introspection by Jean Paul Sartre's hero in Nausea results in derealisation, distortion of time sense and visual illusions. This altered perception of the environment leads on to adoption of a different personal philosophy. It is of interest that two major philosophers described such states, and both regarded them as sources of inspiration rather than a pathological response to stress. Most individuals are vulnerable to such experiences (or should I say 'capable of such experiences'?), but to a variable degree.

It seems the outcome has sometimes been very positive and sometimes rather unsettling.

Alcohol and Drug Resource Centre

DUNCAN WADDINGTON

Windy Oaks

Leeds Road Hospital

Maudsley Street

Bradford BD3 9LH

\section{Clozapine in the community}

SIR: The pharmacology and clinical efficacy of clozapine are extensively described by the contributors to your recent review of the drug (Journal, May 1992, 160, (suppl. 17)). In contrast, the difficulties and implications of widespread prescription outside of research settings, and in particular to patients living in the community, are given scant attention. In view of the increasing use of the drug this would appear to be an essential area for debate.

To service a small group of patients in the community on clozapine could well require the services of an almost full-time nurse to ensure the following precautions are undertaken.

(a) Blood samples must be taken regularly in a patient group who find it notoriously difficult to attend regular appointments.

(b) Adequate time must be allowed for these samples to be posted to the Clozaril Patient
Monitoring Service, analysed, and the result to be sent to the pharmacy dispensing the drug. If no result is obtained, no tablets are dispensed. It is therefore essential that coordination of these events occurs and that accurate reporting systems are in place.

(c) There is close liaison with the pharmacy and also with the doctor to ensure that these steps run smoothly and so that any notifiable change in blood sample results can be brought to the attention of the relevant people immediately.

(d) Patients should receive their prescribed medication following the results of blood tests, which for this patient group may mean that it has to be delivered to their homes in the community.

It may therefore be necessary to redeploy mainstream staff, in order to set up a special clozapine service in every district.

As well as having regular blood tests, patients on clozapine, and their carers, need to know that any episodes of infection are potentially lethal. Firm integrated working relationships should be established with local general practitioners, so that any episodes of physical illness are picked up, and all concerned need to given clear guidelines about what action they should take. Even with such precautions there will be significantly increased risks to patients who are vague or unreliable, or to those who do not have carers in close contact.

In some centres, community practitioners are not registered to prescribe clozapine because they have patients placed in settings which do not have staff cover 24 hours a day seven days a week, and they do not have access to hospital beds. If this cautious approach is justified and accepted, it is likely to have important implications for patients on clozapine. They may remain incarcerated in hospital because of a lack of adequately staffed accommodation.

At the Maudsley hospital, a considerable proportion of pharmacy time is already taken up with administering clozapine prescriptions. Is there enough evidence at this stage of justify the extra staff time and concentration of resources in order to provide the required level of intensive input in the early stages of clozapine prescription? We need to be clear that any such investment is worthwhile in terms of being clinically effective, cost effective (Honigfeld \& Patin, 1990), and in providing a better quality of life for patients (Meltzer et al, 1990), and that tying up such resources will not result in more people having to stay in hospital. 
Honigeld, G. \& PATIN, J. (1990) A two-year clinical and economic follow-up of patients on clozapine. Hospital and Community Psychiatry, 41, 882-885

Meltzer, H. Y., Burnett, S., BAstani, B., et al (1990) Efiects of six months of clozapine treatment on the quality of life of schizophrenic patients. Hospital and Community Psychiatry, 41. 892-897.

Institute of Psychiatry

De Crespigny Park

London SE5 8 AZ

Geraldine STRATHDEE

KAREN JONES

Maudsley Hospital

Denmark Hill

London SE5 8 AZ

\section{ECT anaesthetics}

SIR: I read with interest the audit of ECT in two NHS regions by Pippard (Journal, May 1992, 160, 621-638) which was a fascinating follow-up to his earlier work. As an anaesthetist with responsibility for provision of anaesthesia to an ECT treatment unit, I would like to comment on one small point. Dr Pippard states quite correctly that the use of propofol is probably contraindicated for ECT, because it reduces seizure duration. Therefore methohexitone remains the agent of choice, particularly in view of its proconvulsant potential. Unfortunately, the injection of methohexitone is often painful, and repeated anaesthesia with this agent can be distressing for some patients. Dr Pippard stated that the use of $10 \mathrm{mg}$ lignocaine with anaesthetic induction agents is not recommended because of the potential anticonvulsant activity of this local anaesthetic. The use of lignocaine to modify the pain of injection of methohexitone during anaesthesia for electroconvulsive therapy has been studied (Simpson et al, 1989). We showed that pain on injection of methohexitone occurred in nearly half of the patients, and in a quarter of them pain was reported as moderate or severe. The use of $10 \mathrm{mg}$ lignocaine before or mixed with the methohexitone reduced this significantly. We measured seizure duration using an isolated arm technique and demonstrated that the use of $10 \mathrm{mg}$ lignocaine did not significantly affect seizure duration. In view of these findings I would urge that lignocaine continue to be used routinely when injecting methohexitone into a vein on the dorsum of the hand, particularly when patients are to undergo repeated anaesthesia.

Simpson, K. H., Halsall, P. J., Sides, C. A., et al (1989) Pain on injection of methohexitone. The use of lignocaine to modify pain on injection of methohexitone during anaesthesia for electroconvulsive therapy. Anaesthesia, 44, 688-689.

\section{K. H. SimPSON}

Department of Anaesthesia

St James's University Hospital

Beckett Street

Leeds LS9 7TF

\section{Out-patient ECT for depression in a man with moderate learning disability}

There is little written on the place of ECT in the treatment of mental illness in those with learning disabilities (Lazarus et al, 1990). We would like to report the case of a 69-year-old man with moderate learning disability (IQ of 40).

Case report. Mr X presented with a six-week history of weepiness, lethargy, social withdrawal, weight loss, and poor sleep following an uneventful inguinal hernia repair. On examination he looked sad and described his mood as such. He spoke in monosyllables and complained of aches and pains in his feet (for which no organic cause was found). He had a past history of depression, following a previous inguinal hernia repair at age 61 years, which responded to tricyclic antidepressants. Otherwise he had always been in good health. A diagnosis of depression was made. Dothiepin, $50 \mathrm{mg}$ daily, was started, increasing to $150 \mathrm{mg}$ daily. However, he became more agitated and distressed. He was preoccupied with being unable to swallow, believed he had no throat and ate very little. He lost over $13 \mathrm{~kg}$ (two stones) in weight. His self-care skills deteriorated and he became doubly incontinent. The dothiepin was discontinued after two months and replaced with fluoxetine, $20 \mathrm{mg}$ daily, increasing to $40 \mathrm{mg}$ daily with no improvement after one month. At this stage his permission to commence ECT was sought and given. He received 11 bilateral treatments. After the first treatment a marked improvement in his appetite was noted with a reduction in his agitation. This continued to improve, as did his sleep; his bodily preoccupations and delusions then faded, followed lastly by a reduction of his social withdrawal. Three months later he is considered to be his 'old self' and is on fluoxetine, $40 \mathrm{mg}$ daily.

This case adds to the small literature on the use of ECT in those with learning disability and mental illness. The majority of the cases described are, as is this one, of major depression. Goldstein \& Jensvold's (1989) case bears particular similarities in that their patient's depression was seemingly precipitated by a surgical procedure. Kearns (1987) described a case of a man with learning disabilities with Cotard's syndrome who responded to ECT. In the present case the patient similarly denied the existence of part of his body (his throat). Our patient had ECT as an outpatient. Lazarus et al (1990) advocate the use of this, 